\title{
WTI and Brent Futures Pricing Structure
}

\author{
Daniel P. Scheitrum ${ }^{\mathrm{a}, *}$, Colin A. Carter ${ }^{\mathrm{b}}$, Cesar Revoredo-Giha ${ }^{\mathrm{c}}$ \\ ${ }^{a}$ The University of Arizona, Tucson, AZ 85721 \\ ${ }^{b}$ University of California, Davis, One Shields Avenue, Davis, CA 95616 \\ ${ }^{c}$ Scotland's Rural College (SRUC), Kings Buildings, West Mains Road, Edinburgh EH9 3JG, UK
}

\begin{abstract}
WTI and Brent crude oil futures are competing pricing benchmarks and they jockey for the number one position as the leading futures market. The price spread between WTI and Brent is also an important benchmark itself as the spread affects international trade in oil, refiner margins, and the price of refined products globally. In addition, the shapes of the WTI and Brent futures curves reflect supply and demand fundamentals in the U.S. versus the world market, respectively.
\end{abstract}

On the analysis of the relationship between the two futures prices, we identify a structural break in the WTI-Brent price spread in January 2011 and a break in the corresponding shapes of the futures curves around the same time. The structural break was a consequence of a dramatic rise in U.S. production due to fracking, a series of supply disruptions in Europe, binding storage constraints, and the U.S. crude oil export ban. These events are studied in the context of a simulation model of world oil prices. We reproduce the stylized facts of the oil market and conclude that the 2011 break in pricing structure was consistent with standard commodity storage theory.

Keywords: crude oil futures, commodity storage, WTI, Brent, competitive storage model

${ }^{*}$ Corresponding author: dpscheitrum@email.arizona.edu. 
1

2

3 West Texas Intermediate (WTI) and Brent crude. As benchmarks, WTI and Brent provide a

4 reference price against which oil around the world is traded at a premium or discount. WTI

5 is primarily traded on the NYMEX (CME Group) while Brent is primarily traded on the

6 Intercontinental Exchange (ICE). The CME Group and ICE both cross list WTI and Brent.

7 However, the CME accounts for over $80 \%$ of WTI volume and the ICE accounts for about $\approx 90 \%$ of the Brent trading volume.

9

10

11

The pricing point for WTI is delivery into either a pipeline or storage facility in Cushing, Oklahoma. Brent crude specifies delivery onto a vessel at the Sullom Voe oil terminal on the Shetland Islands in the North Sea. The chemical characteristics of Brent and WTI are nearly identical, with Brent crude being the slightly less sulfurous of the two. Annual trading volume for each of the contracts is displayed in Figure 1 where it is shown that for three recent years (2012-2014) Brent displaced WTI as the most heavily traded oil futures market. During this time period, the U.S. government's Energy Information Administration (EIA) abandoned WTI for its reference oil price, and substituted the North Sea Brent contract, in its 2013 Annual Energy Outlook. The reasoning was that WTI was somewhat disconnected from the global market. At the time Brent was a superior benchmark because imported crude into the eastern and western U.S. coastal markets and refined products in the U.S. are priced off the global market. But shifting to Brent as a reference price was not ideal because oil production in the North Sea is dwindling due to aging oil fields in that region.

Crude oil sold in the U.S. is priced off the WTI contract, while oil sold internationally is typically priced off Brent. Therefore the spread between the two is a very important metric in the global oil complex. The spread reflects the competitiveness of U.S. in the world market and in addition the WTI-Brent price spread is an indicator of refiner profitability in the U.S. 


\section{Figure 1: WTI and Brent Annual Futures Contract Trading Volumes}

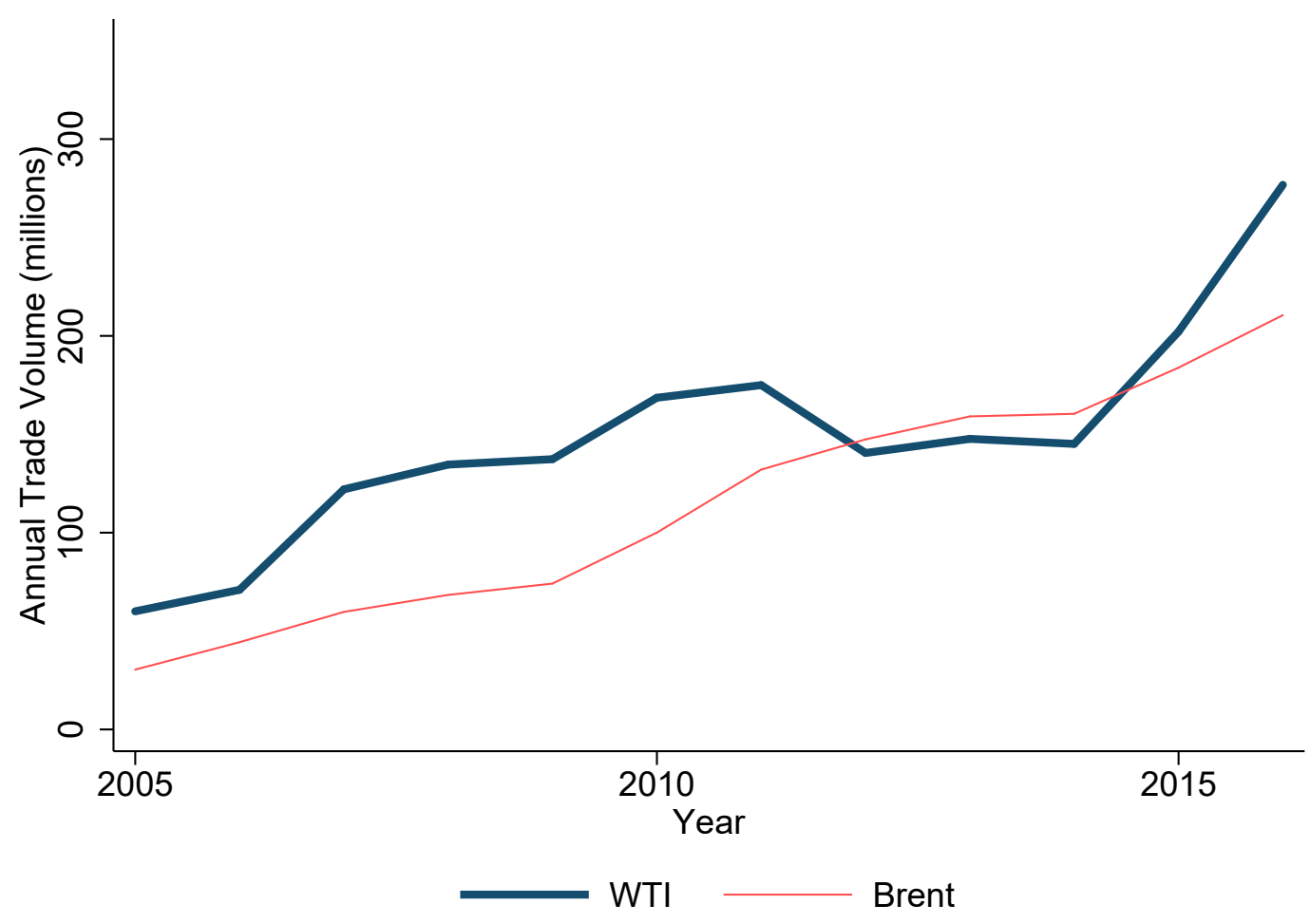

Source: https://www.theice.com/marketdata/reports/7 for Brent and Bloomberg for WTI.

versus world market. Refiner profits are impacted by the spread because their input (oil) could be benchmarked off WTI (depending on the source) but their output (gasoline or other refined products) could be more closely benchmarked to Brent. In this paper we study the WTI-Brent price spread and the shapes the futures curves for each of the two contracts. Our specific aim is to explain what happened in 2011 when the spread diverged from historical levels, sending WTI to more than a $\$ 20$ discount under WTI and resulting in the WTI being viewed as a broken benchmark for a time. At the same, time the shape of the WTI and Brent futures curves became dissimilar from one another, with different slopes, which was unusual. settlement points are separated by over four thousand miles and the delivery specifications differ substantially. Brent crude can be readily transported anywhere in the world and thus its 
37

spot price is more correlated with port and coastal grades of crude oil (The Intercontinental Exchange, 2013). Alternatively, WTI is more responsive to U.S.-specific supply and demand fundamentals and infrastructure issues. Further, the WTI pricing point is co-located with substantial above-ground storage, 73 million barrels of storage capacity (EIA, 2016c). The Brent location is more of a just-in-time production model with only 8.4 million barrels of available storage (Olsen, 2012, BP, 2016). Conceptually, the vastly different storage facilities could give rise to alternative inter-temporal price spreads in one market versus the other. The law of one price suggests that the spot prices for these nearly equivalent grades of crude oil should differ by no more than the transactions costs of transporting oil from one market to another. This is why the spot prices were so closely linked prior to 2011, when the U.S. was a major net importer of oil (Fattouh, 2010).

Inter-temporal prices are linked through storage (Working, 1949, Brennan, 1958, Wright and Williams, 1982) and spatial prices are linked by trade (Makki, Tweeten and Miranda, 1996, Miranda and Glauber, 1995). There have been other cases in the commodities space where the law of one price has broken down, but typically, these are short lived events. For instance, in early 2014 natural gas prices at the Algonquin citygate hub serving Boston reached about $\$ 25$ per mmBTU compared to $\$ 5$ per mmBTU in Henry Hub due to pipeline capacity constraints (EIA, 2016b). However, this price differential lasted only a matter of months compared to the lengthy WTI-Brent differential.

Figure 2 shows the log relative spot price of WTI and Brent from 1993 to 2016. The relative price remained relatively stable from the beginning of the series until some time in early 2011 where the relative price sharply falls, indicating a divergence in the spot prices. Figure 2 also includes a dashed line at the January 6, 2011 breakpoint which is discussed in Section 2 .

1 Not only did the spot prices diverge in early 2011, but so did the shape of the futures curves for both WTI and Brent. We observe a marked difference between inter- 
Figure 2: Log Relative Price of WTI and Brent Spot Prices

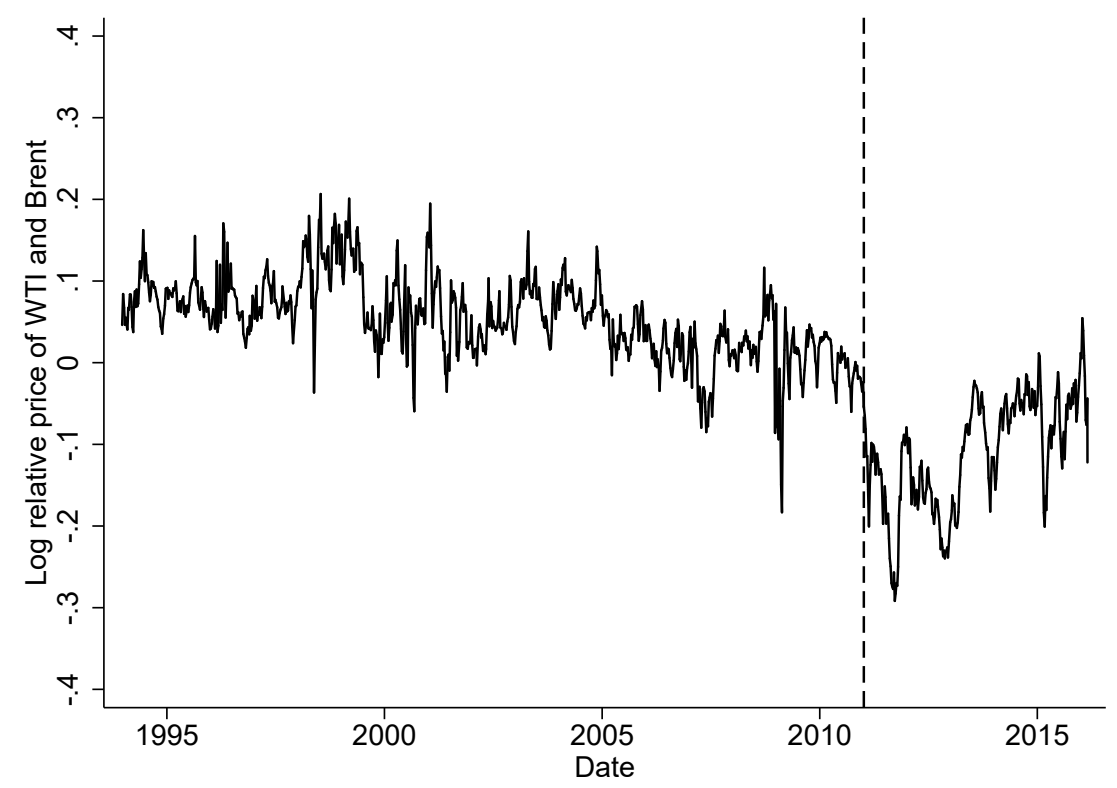

Note: Log of the ratio of WTI and Brent weekly spot prices. Dashed line indicates January 6, 2011. Source: Data obtained from United States Energy Information Administration.

temporal futures price spreads for WTI and Brent, shown below in Figure 3. We define the inter-temporal price spread for each crude oil grade as the fourth month futures price minus the front month price. We choose this measure of inter-temporal price spread to yield a three-month time horizon within which trade and storage decisions can be made. We observe that in 2011, the price spread for WTI was positive, or in "contango," and the spread for Brent was negative, or in "backwardation." In the early portion of the sample, these contracts exhibit similar price spreads where typically they were either both in contango or both in backwardation at any given time. The contango structure of the WTI futures curve is indicative of an oversupplied market, that is the market is putting a premium on oil delayed for sale in the future. Whereas, the Brent in backwardation indicated the market was placing a premium on immediate delivery of oil. Figure 3 shows that, around the same time the spot prices diverged, the shape of the futures curves for WTI and Brent also diverged. WTI remained in contango and Brent went into backwardation. This divergence of WTI and Brent prices led some to question the legitimacy of WTI as the global oil benchmark, 
Figure 3: WTI and Brent, Weekly Three-Month Price Spreads

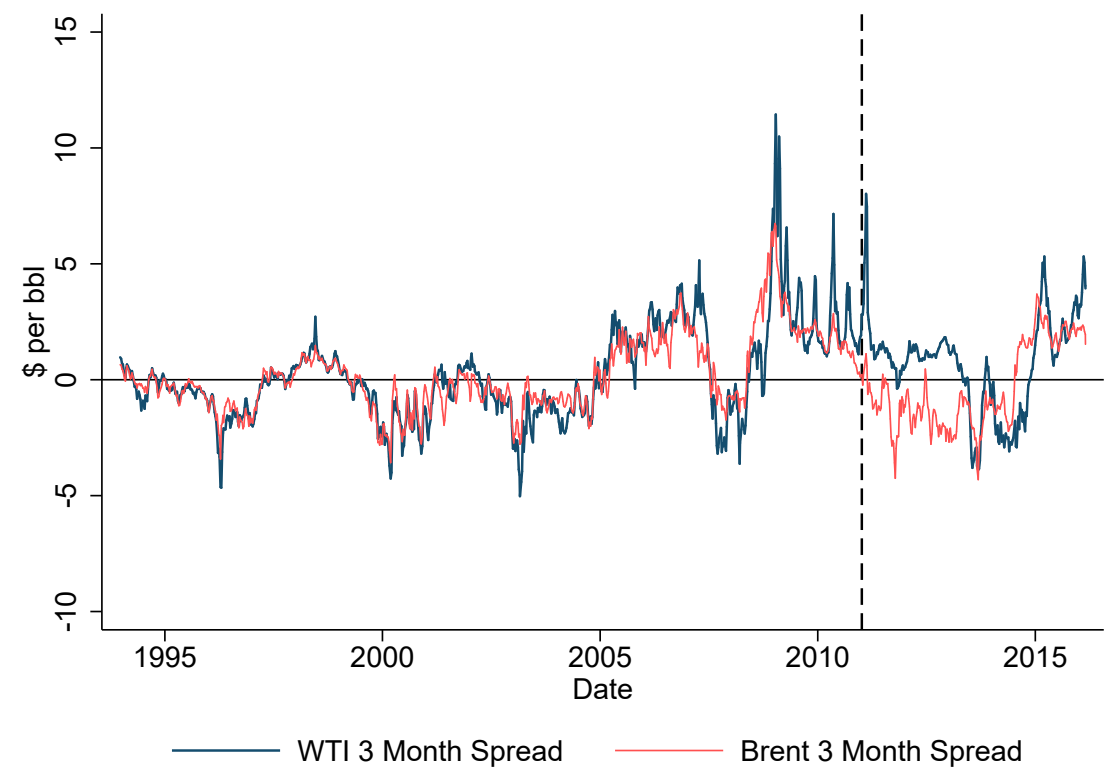

Note: The three-month price spread is calculated as the futures price for delivery four months in the future minus the futures price for delivery one month in the future. Dashed line indicates January 6, 2011.

Source: Data obtained from Quandl.com.

77 suggesting that Brent should take its place (Kilian, 2016). However, Kilian (2016) notes that Brent suffers from its own drawbacks such as declining North Sea production leading to low

liquidity, and the continual broadening of the definition of the Brent benchmark to include lower grades of crude. Kilian (2016) wrote that it is "unclear whether there remains enough oil in the North Sea to sustain a Brent benchmark in the long run" (p. 33).

We hypothesize that a series of events, beginning in the late 2000 s, led to a situation where the combined effect was a break in integrated WTI and Brent markets. The shale revolution greatly increased U.S. domestic oil production starting in 2008 (Brown and Yücel, 2013). A thorough overview of the shale revolution can be found in Kilian (2016) and Alquist and Guénette (2014). As U.S. production rose, more oil began flowing to Cushing, OK than could be refined and then moved via pipeline. Therefore, crude oil stocks in Cushing began to climb (Wilmoth, 2012). In March 2011, storage capacity utilization reached 91\% in Cushing, OK (EIA, 2015). 
At the same time, Europe was experiencing negative supply shocks. The Libyan Crisis disrupted production and this incident persisted much longer than expected (Meyer, 2011). Nigerian pipeline sabotage also disrupted supply (Vidal, 2011). In addition, bad weather in the North Sea caused production outages (Meyer, 2011). These supply disruptions resulted in severe drawdowns of Brent inventories (Blas and Blair, 2011).

Prior literature has identified the U.S. shale revolution, non-U.S. production disruptions, U.S. infrastructure and transportation bottlenecks, the U.S. export ban, reweighting of the S\&P GSCI commodity index in favor of Brent, and the Dow Jones UBS commodity index including Brent for the first time, as explanations for the divergence of the WTI and Brent prices (Alquist and Guénette, 2014, Büyüksahin et al., 2013, Chen, Huang and Yi, 2015, Kilian, 2016, Ye and Karali, 2016).

We develop a stylized, simulation model of world oil prices that we parameterize and calibrate to represent the characteristics of the crude oil market before the structural break. We impose features of the key stylized facts: positive production shocks in the U.S., negative production shocks in Europe, maximum and minimum storage constraints, and a U.S. export ban. We then simulate the model and compare the results with the characteristics of the oil market before and after the structural break. We are able to successfully reproduce the structural break in the oil market.

This paper is organized as follows: in Section 2, we present stylized facts of the world oil market and we test for and identify a break in cointegration between WTI and Brent daily spot prices as well as daily nearby futures prices. In Section 3, we present our hypotheses as to why there was a structural break. Next, in Section 4 we develop a stylized model of world oil prices based upon the competitive storage model employed by Gustafson (1958), Wright and Williams (1982), Deaton and Laroque (1992), and the extensions by Miranda and Glauber (1995) and Makki, Tweeten and Miranda (1996) which incorporate trade into the model. Section 5 presents the results of our simulation of the model and compares them 
to the key stylized facts of the oil market following the structural break. Finaly, Section 6 concludes.

\section{Stylized facts of the world oil market}

Key stylized facts related to the WTI and Brent markets are shown in Table 1. When comparing average data for the three years before the 2011 price break to the average for the three years following, U.S. production increased by $43 \%$ and North Sea production decreased by $29 \%$. Storage levels at the WTI pricing terminal increased by $32 \%$ and storage levels in OECD Europe declined by 4\%. ${ }^{1}$ Exports from the North Sea to the U.S. declined by $76 \%$ and the average spot price premium for WTI over Brent fell from $\$ 0.92$ to $-\$ 11.18$. The shape of the forward curve also experienced a shift as the percent of trading days that WTI was in contango fell from $90 \%$ to $69 \%$, whereas for Brent it fell from $92 \%$ to $45 \% .^{2}$ In the years following the price break, Brent was in backwardation more often than in contango. Futures trading volume in the WTI front month contract fell by 19\%, whereas the Brent front month (the contract for most immediate delivery) trading volume increased by $61 \%$.

When linked by trade, the spot prices of WTI and Brent crude should be arbitraged. Since the inception of the Brent crude benchmark in 1993 through 2011, this was largely true. The 52-week rolling correlation between the weekly spot prices of WTI and Brent are presented in Figure $4 .^{3}$ It is apparent that the correlation between these two price series does not deviate much from the mean of 0.96 up until some point in 2011 when the relationship broke down. The correlation dropped and remained persistently depressed following the start

\footnotetext{
${ }^{1}$ The ideal measure for Brent storage is storage levels at the Sullom Voe terminal, however, these data are unavailable. As a proxy, storage levels for OECD Europe as a whole declined between these two time periods.

${ }^{2}$ Percent of trading days in contango is measured as the proportion of trading days where the settlement price for the futures contract four months ahead is greater than the settlement price of the futures contract one month ahead.

${ }^{3} \mathrm{On}$ a given week, the 52 -week rolling correlation calculates the correlation between two series for the past 52 weeks.
} 


\section{Table 1: WTI and Brent Oil Markets, Stylized Facts}

\begin{tabular}{lccc}
\hline & $2008-2010$ & $2012-2014$ & $\% \Delta$ \\
\hline $\begin{array}{l}\text { Production } \\
\quad \text { U.S. (thousand bbl/day) }\end{array}$ & 5,277 & 7,546 & $+43 \%$ \\
$\quad$ North Sea (thousand bbl/day) & 3,702 & 2,650 & $-28 \%$ \\
$\begin{array}{l}\text { Storage } \\
\quad \text { Cushing, OK (thousand bbl) }\end{array}$ & 28,065 & 37,362 & $+33 \%$ \\
$\quad$ OECD Europe (thousand bbl) & 332,333 & 317,467 & $-4 \%$ \\
International Trade & & & \\
$\quad$ North Sea to U.S. (thousand bbl/day) & 140 & 34 & $-76 \%$ \\
Prices & & & \\
$\quad$ WTI-Brent Average Spot Premium & $\$ 0.92$ & $-\$ 11.18$ & $-1,315 \%$ \\
$\quad \begin{array}{l}\text { Percent of Trading Days in Contango } \\
\quad \text { WTI }\end{array}$ & $90 \%$ & $69 \%$ & $-23 \%$ \\
$\quad$ Brent & $92 \%$ & $45 \%$ & $-50 \%$ \\
$\quad$ Front Month Trading Volume & & & \\
$\quad$ WTI & 285,591 & 232,665 & $-19 \%$ \\
$\quad$ Brent & 110,570 & 178,326 & $+61 \%$ \\
\hline
\end{tabular}

Source: U.S. production data (EIA, 2016f), North Sea production data (EIA, 2016a), Cushing, OK storage data (EIA, 2016g), and North Sea to U.S. international trade data (EIA, 2016e) are from the U.S. Energy Information Administration. North Sea production and international trade data are computed as the sum of country-specific values for Denmark, Germany, the Netherlands, Norway, and the United Kingdom. OECD Europe storage data are from the IEA Oil Market Reports for February 2012 and February 2016 (IEA, 2012, IEA, 2016). The WTI-Brent average spot premium is calculated as the difference the WTI spot price minus the Brent spot price per the Energy Information Administration (EIA, 2016d). Percent of trading days in contango is based on the portion of days where the fourth month futures price exceeds the front month futures price based on daily futures settle prices for the CME WTI contract and ICE Brent contract obtained from Quandl.com. Front month trading volume for the CME WTI contract and ICE Brent contract are based on daily trading volume obtained from Quandl.com.

of 2011. The absolute prices are presented in Figure 5.

We analyzed the long-term relationship between WTI and Brent series; as they were non-stationary ${ }^{4}$ we tested for cointegration between them using weekly spot prices and performing the two-step Engle-Granger test for cointegration (Engle and Granger, 1987). We suspect that the two price series are cointegrated during the early portion of our sample, but the cointegration degrades at some point. To test for a break in the cointegration between

\footnotetext{
${ }^{4}$ We performed the augmented DF-GLS test on the daily spot prices from 1993 to 2016 and found both series non-stationary (Dickey and Fuller, 1979, Elliott, Rothenberg and Stock, 1992). The DF-GLS test statistic for WTI was -1.577 and for Brent -1.307 , therefore it was not possible to reject the hypothesis of non-stationarity in levels.
} 
Figure 4: 52-week Rolling Correlation of WTI and Brent Weekly Spot Prices

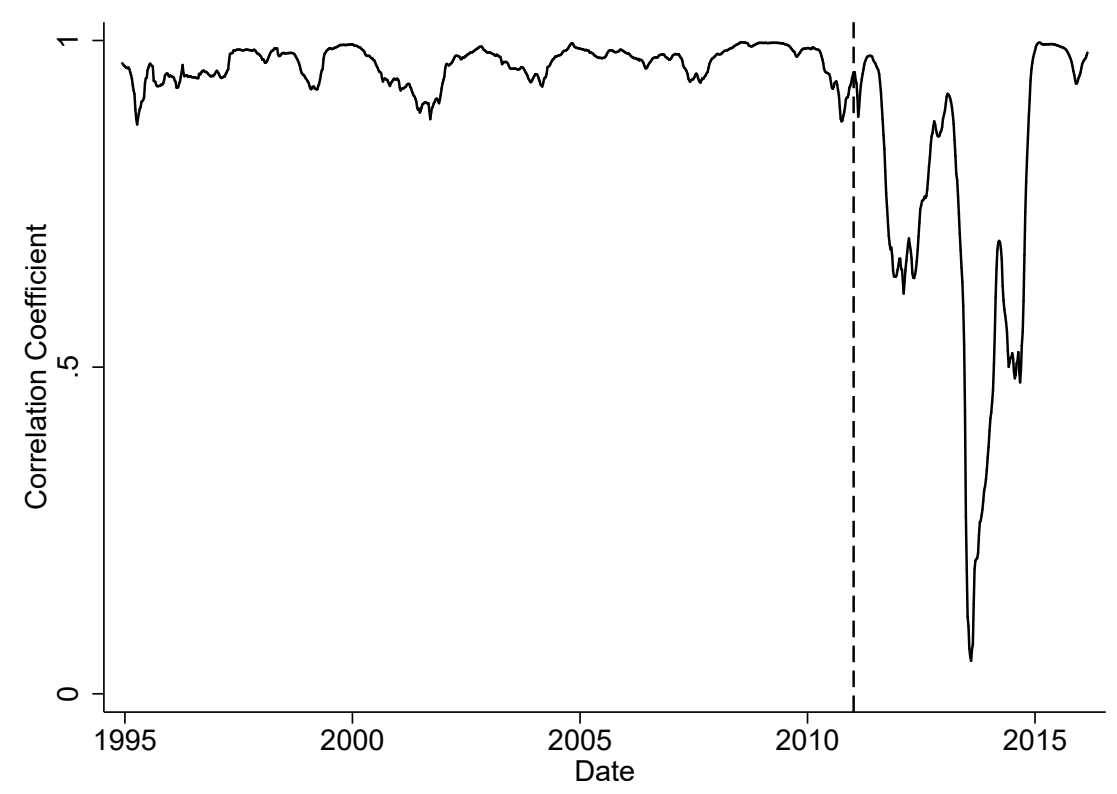

Note: Dashed line indicates January 6, 2011.

Source: Data obtained from United States Energy Information Administration.

Figure 5: WTI and Brent Weekly Spot Prices

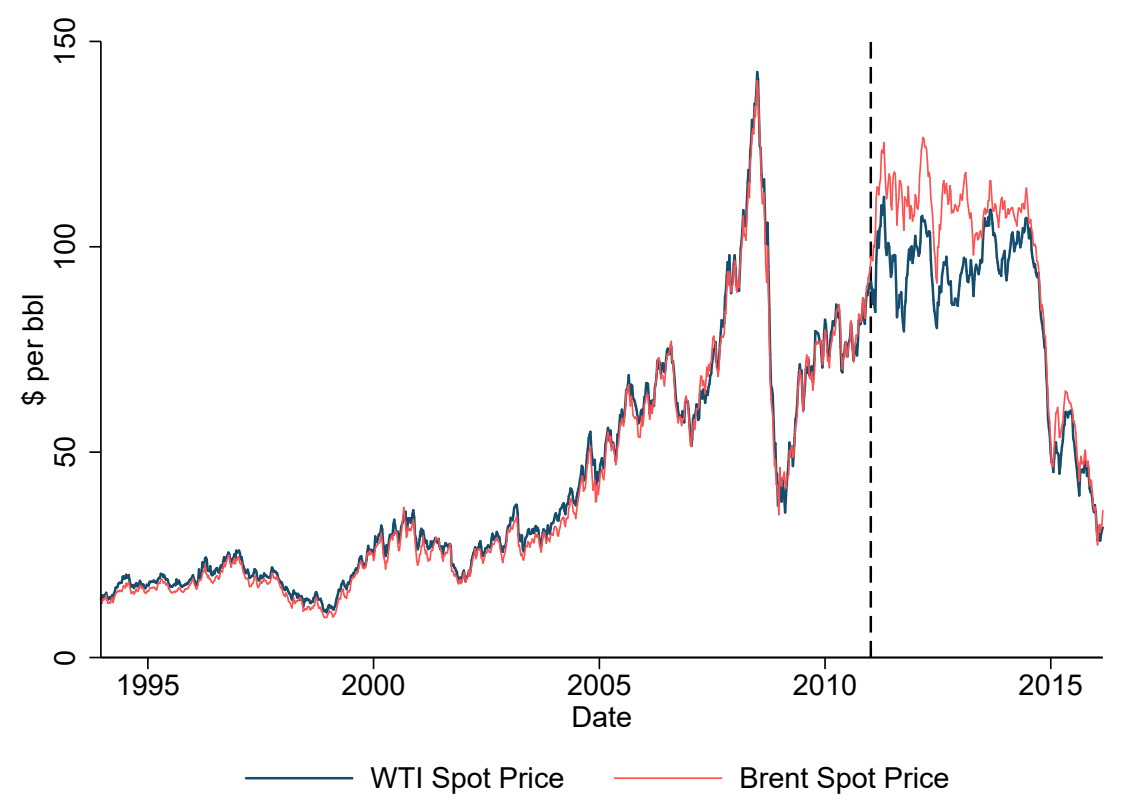

Note: Dashed line indicates January 6, 2011.

Source: Data obtained from United States Energy Information Administration. 
WTI and Brent, we perform a supremum Wald test for a structural break at an unknown break date using symmetric trimming of $15 \%$ in the equation

$$
W T I_{t}=\alpha+\beta \text { Brent }_{t}+u_{t}
$$

where $W T I_{t}$ is the daily spot price of WTI at time $t$, and Brent $_{t}$ is the daily spot price of Brent at time $t$. Our test finds a breakpoint on January 6, 2011 which is consistent with other studies which have identified December 2010 as the date of a structural break in the WTI-Brent price spread (Büyüksahin et al., 2013, Chen, Huang and Yi, 2015, Ye and Karali, 2016) and in WTI-Brent cointegration (Chen, Huang and Yi, 2015).

To more formally test for a breakdown in the cointegration between these series, we repeat the Engle-Granger cointegration test for the periods before and after the breakpoint. We find strong evidence of cointegration between WTI and Brent in the period before the January 6, 2011 breakpoint and we fail to reject the hypothesis of no cointegration in the period after the breakpoint, at the $1 \%$ significance level. Test statistics for the stationarity and cointegration tests for the pre- and post-breakpoint periods are presented in Table 2 . As a robustness check, we test for a structural break in the cointegration of Brent and WTI daily spot prices using the Gregory-Hansen test (Gregory and Hansen, 1996). We perform the Gregory-Hansen test on Equation 1 allowing for structural change in the level and slope of the cointegrating relationship and reject the null hypothesis of no cointegration in favor of a structural break on January 10, 2011 at the 1\% significance level.

Turning to the futures market, the 52-week rolling correlation between the front month WTI and Brent future prices is reported in Figure 6 and for the fourth month in Figure 7. We find statistical evidence of a structural break in the relationship between the WTI and Brent front month futures prices on January 6, 2011 as well as between the fourth 
Table 2: Tests for Stationarity and Cointegration

\begin{tabular}{lcc}
\hline Test & Pre-Breakpoint & Post-Breakpoint \\
\hline WTI Stationarity & -2.263 & -0.830 \\
Brent Stationarity & -1967 & -0.664 \\
WTI-Brent Cointegration & $-8.066^{* *}$ & -2.650 \\
\hline$* p<0.05,{ }^{* *} p<0.01$ & &
\end{tabular}

Stationarity and cointegration tests are conducted on daily WTI and Brent spot prices per the Energy Information Administration (EIA, 2016d). The Pre-Breakpoint time period is December 17, 1993 to January 5, 2011 and the Post-Breakpoint time period is January 7, 2011 to February 26, 2016. Test statistics reported above are the results of DF-GLS tests allowing for a trend and including lag terms as specified by the Schwarz Criterion. The results are preserved under alternative choices of lag length and restrictions on trend.

\footnotetext{
${ }^{5}$ We estimate structural breaks for the front and fourth month contracts using the supremum Wald test for a structural break at an unknown break date using symmetric trimming of $15 \%$. The front month structural break and fourth month structural break are also statistically significant at the $<0.0001 \%$ level.
} 
Figure 6: 52-week Rolling Correlation of WTI and Brent Weekly Front Month Futures Prices

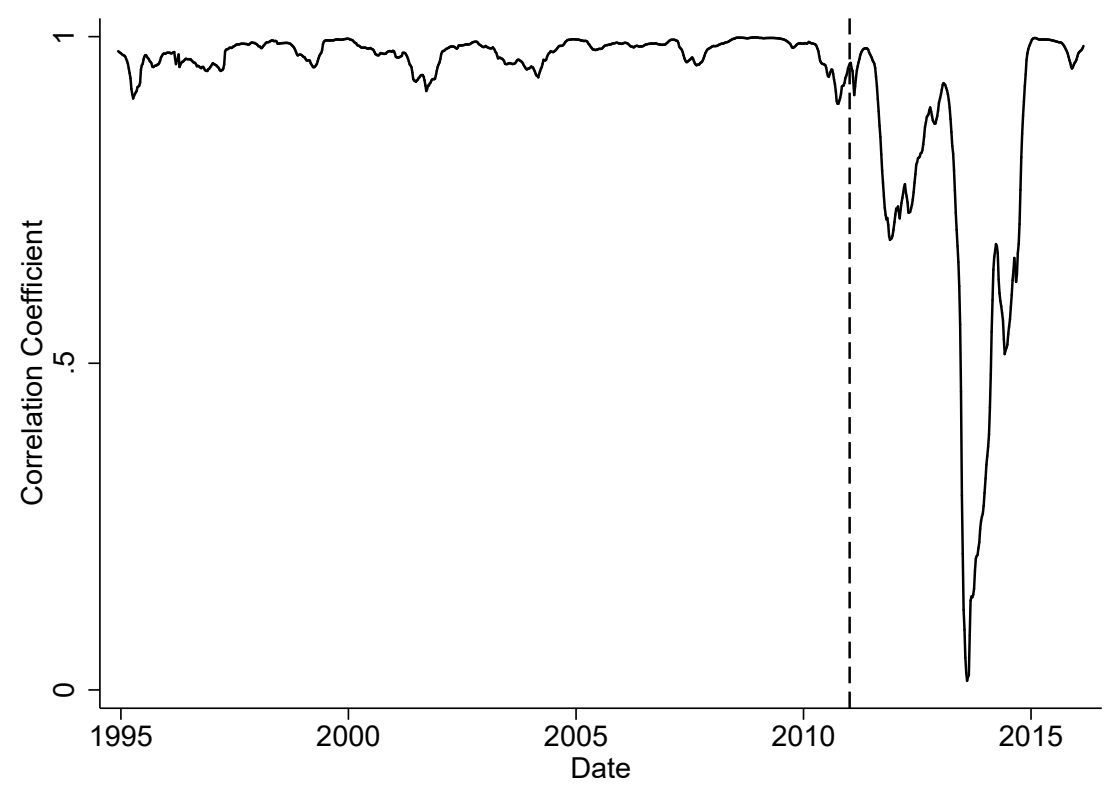

Note: Dashed line indicates January 6, 2011.

Source: Data obtained from Quandl.com.

Figure 7: 52-week Rolling Correlation of WTI and Brent Weekly Fourth Month Futures Prices

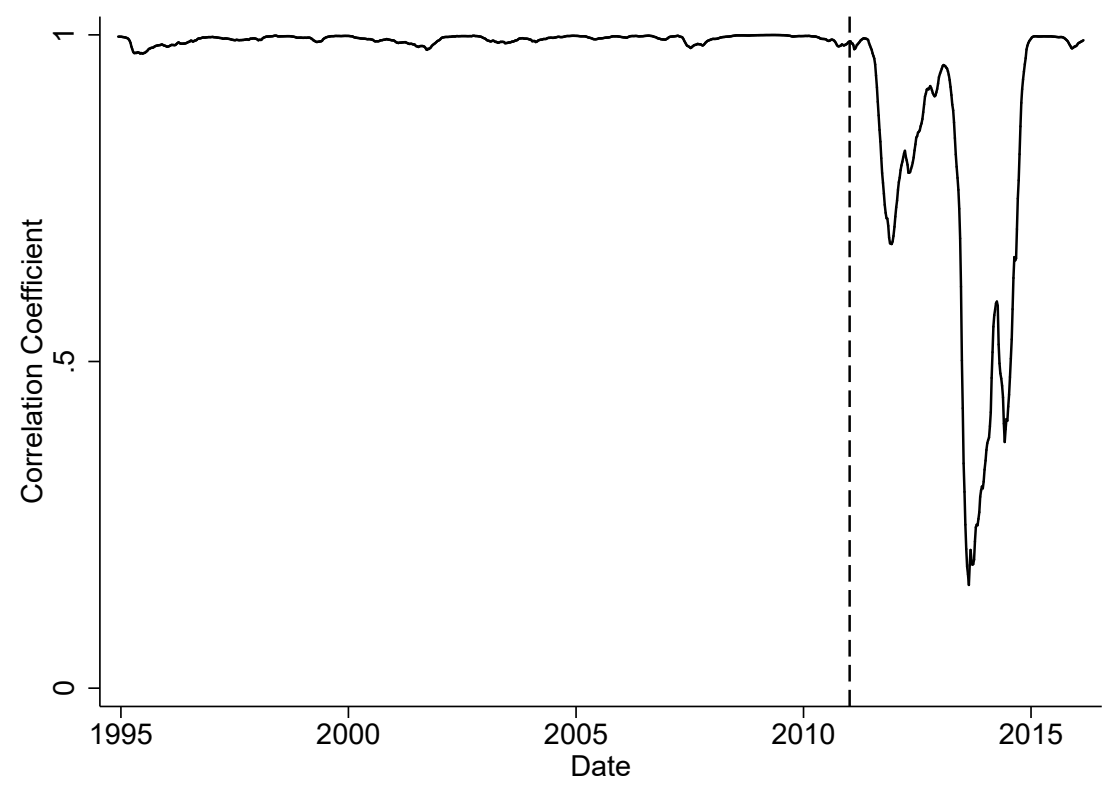

Note: Dashed line indicates January 25, 2011.

Source: Data obtained from Quandl.com. 
price, futures price, and inter-temporal spread relationships in the same direction as the supply shocks. That is, the negative demand shock experienced by the U.S. exacerbates the impact of the positive supply shock on the futures pricing relationship. For the EU, the positive demand shock exacerbates the impact of the negative supply shock. In Section 5.1, we describe an alternative specification of our competitive storage model where we implement structural change in the form of demand shifts rather than supply shifts and our results are robust to this change in specification.

The supply shocks in the U.S. and EU oil markets resulted in the price of WTI falling below the price of Brent by an amount that far exceeded shipping costs of about $\$ 2$ per barrel (Scheid, 2014). The average price difference between 2000 and 2010 had WTI at a premium of $\$ 1.40$ per bbl. The price difference between WTI and Brent reached the extreme of WTI at a discount of $\$ 29.59$ per bbl on September 23, 2011. However, due to the U.S. crude oil export ban, this price difference was not arbitraged away. Traders were unable to move oil from the United States to Europe or elsewhere to correct the price differential which lasted until 2015. As a consequence of the unexpected positive oil supply shocks in the U.S., storage capacity in Cushing, OK reached its maximum. One curious element of the steep contango in the United States is that with the relatively new production boom in historically non-producing regions (e.g. North Dakota) why would these producers not simply "store" their oil in place rather than extract and deliver into a market that indicate higher prices would await in a few months time. Nevertheless, these producers in these regions did extract their oil during despite facing a steep contango. When there is no opportunity to put oil into storage, it creates pressure to sell immediately thus driving down the spot price relative to the futures price. The contrary is true of the Brent market; as unexpected supply disruptions persisted and continued to draw down inventories, this put upward pressure on the spot price of oil relative to the futures prices. We theorize that had there been no export ban, or if the U.S. had plenty of excess storage capacity and Europe had plenty of crude oil in storage, the integration of the two markets would have persisted. 


\section{A stylized model of world oil prices}

As Deaton and Laroque $(1992,1996)$ employed the competitive storage model to reproduce the stylized facts of autocorrelation and price spikes in commodity prices, we employ the competitive storage model to reproduce the Brent-WTI oil market pricing structure linked by trade. As in Miranda and Glauber (1995), we conceptualize a two-region oil market allowing competitive interregional trade, competitive storage, lagged production decisions and uncertain output and prices. While a two-region model is a simplification of the complex geography of the world oil market, this representation is useful in isolating the impacts of barriers to spatial and inter-temporal arbitrage. Since models of trade and storage under uncertainty do not have analytical solutions (Gustafson, 1958, Deaton and Laroque, 1992, Miranda and Glauber, 1995, Gardner, 1979), we solve and simulate the competitive storage model numerically using the Rational Expectations Complementarity Solver created by Christophe Gouel (2012). In order to capture the nature of the oil market at the time of the market pricing anomaly, we impose the restriction on trade that United States may not export oil and we impose constraints on storage such that storage levels may not fall below zero or exceed some maximum capacity specific to each region. For each region $i=1,2$ and period $t$, market price is denoted by $P_{i, t}$, planned production by $H_{i, t}$, ending stocks by $S_{i, t}$, consumption by $C_{i, t}$, exports from region $i$ by $X_{i, t}$ and the discount rate is denoted by $r$. The quantity of oil available in each region at the beginning of each period, $A_{i, t}$, is equal to the ending stocks of last period plus current production which is determined by a multiplicative, exogenous shock, $e_{i, t}$, on a production decision last period:

$$
A_{i, t}=S_{i, t-1}+H_{i, t} e_{i, t}
$$

Available oil at the beginning of the period plus current period imports must equal current period consumption plus ending stocks plus current period exports: 


$$
A_{i, t}+X_{\sim i, t}=C_{i, t}+S_{i, t}+X_{i, t} .
$$

In the above market clearing condition, $X_{\sim i, t}$ denotes imports into region $i$. We assume isoelastic demand functions in each region:

$$
C_{i, t}=D_{i} \times\left(P_{i, t}\right)^{\varepsilon_{i}}
$$

with demand parameterized by the constants $D_{i}$ and $\varepsilon_{i}$. We also assume isoelastic supply functions in each region:

$$
H_{i, t}=g_{i} \times\left(\frac{E_{t}\left[P_{i, t+1} e_{i, t+1}\right]}{(1+r)}\right)^{\eta_{i}}
$$

with the supply functions parameterized by the constants $g_{i}$ and $\mu_{i}$ for each region. The price of oil in the United States can only exceed the price of oil in Europe by, at most, the amount of shipping costs. Therefore, either the WTI minus Brent price spread is less than shipping costs or exports from Europe to the U.S. are greater than zero. The spatial arbitrage complementary slackness condition is then:

$$
X_{2, t} \geq 0 \quad \perp \quad P_{1, t}-P_{2, t} \leq \tau,
$$

where $\tau$ is the per-barrel shipping cost. ${ }^{6}$ There is no spatial arbitrage condition allowing for trade from the United States to Europe while the crude oil export ban is in place. When the ban is lifted, the spatial arbitrage condition for trade from the United States to Europe is

\footnotetext{
${ }^{6}$ The symbol $\perp$ indicates that both weak inequalities hold and at least one holds with equality.
} 


$$
X_{1, t} \geq 0 \quad \perp \quad P_{2, t}-P_{1, t} \leq \tau .
$$

247

In this model, we have considered linear shipping costs and no transport constraints beyond the U.S. export ban, though nonlinear shipping costs and transportation constraints could be included.

Similar to the trade arbitrage condition above, merchants in both markets can store crude oil and will do so if the discounted expected price of oil in that market exceeds the current price by storage costs within the bounds of minimum, 0 , and maximum, $\bar{S}_{i}$, storage levels. The inter-temporal arbitrage complementary slackness conditions are then:

$$
0 \leq S_{i, t} \quad \perp \quad \frac{E\left[P_{i, t+1}\right]}{1+r}-P_{i, t} \leq k,
$$

$$
S_{i, t} \leq \bar{S}_{i} \quad \perp \quad k \leq \frac{E\left[P_{i, t+1}\right]}{1+r}-P_{i, t}
$$

where $k$ is the per-barrel cost of storage.

The multiplicative, exogenous shocks, $e_{i, t}$, are assumed to be independent over time and across regions and distributed as:

$$
\left[\begin{array}{l}
e_{1, t} \\
e_{2, t}
\end{array}\right] \sim \mathcal{N}(\mu, \Sigma) .
$$

We calibrate the model to pre-2011 market conditions characterized by: (1) low variance in WTI-Brent spot price spread, (2) WTI price slightly higher than Brent, (3) inter-temporal price spreads highly correlated, (4) oil trade in only one direction, and (5) minimum and 


\footnotetext{
${ }^{7}$ Minimum storage constraint is zero in both markets. The maximum level of storage in the United States, $\bar{S}_{1}=2$, is set to be ten times larger than the maximum level of storage in Europe, $\bar{S}_{2}=0.2$, to reflect actual market conditions.

${ }^{8}$ We have also considered specifcations for the covariance matrix which are not symmetric nor independent and find that these alternate specifications do not affect our results.
}

\begin{tabular}{llr}
\hline Parameter & Symbol & Value \\
\hline Per Barrel Storage Cost & $k$ & 0.06 \\
Per Barrel Shipping Cost & $\tau$ & 5 \\
Supply Elasticity 1 & $\eta_{1}$ & 0.2 \\
Supply Coefficient 1 & $g_{1}$ & 2,201 \\
Supply Elasticity 2 & $\eta_{2}$ & 0.2 \\
Supply Coefficient 2 & $g_{2}$ & 1,550 \\
Demand Elasticity 1 & $\varepsilon_{1}$ & -0.2 \\
Demand Coefficient 1 & $D_{1}$ & 12,997 \\
Demand Elasticity 2 & $\varepsilon_{2}$ & -0.2 \\
Demand Coefficient 2 & $D_{2}$ & 8,649 \\
Maximum Storage 1 & $\bar{S}_{1}$ & 73 \\
Maximum Storage 2 & $\bar{S}_{2}$ & 8.4 \\
Discount Rate & $r$ & $2 \%$ \\
Mean Shock & $\mu$ & $\left(\begin{array}{l}1 \\
1\end{array}\right)$ \\
Shock Covariance Matrix & $\Sigma$ & 0.025 \\
0
\end{tabular}

\section{Simulation Results}


United States and lower than expected production in Europe, we select 150 random shocks from the distribution $\mathcal{N}\left(\mu^{\prime}, \Sigma\right)$ where $\mu^{\prime}=\mu+\left(\begin{array}{c}0.075 \\ -0.075\end{array}\right)$. That is, starting in period 100 and running to the end of the simulation, the mean production shock in the United States is increased by 1.5 standard deviations and the mean production shock in Europe is decreased by 1.5 standard deviations. Lastly, to illustrate the consequence of the U.S. crude oil export ban, beginning at period 150 and running to the end of the simulation, we remove the export ban and allow trade to flow from the U.S to the EU. The storage constraints are imposed by limiting $S_{i}$ to $\left[0, \bar{S}_{i}\right]$ where $\bar{S}_{i}<\infty$. The export ban is imposed by restricting $X_{1, t}=0$ for the periods where the export ban is in place, where $X_{1, t}$ is the quantity of exports from the U.S. to Europe in time $t$. The imposition of the shifts in production and lifting the export ban partition the sample into three regimes. Regime 1, from period 1 to 100, is considered to be the reference case where the production remains unaltered and the export ban is in place. Regime 2, from period 101 to 150, has U.S. production elevated and EU production depressed along with the export ban in place. Regime 3, from period 151 to 250, has U.S. production elevated and EU production depressed along with no restrictions on trade between U.S. and the EU.

Given the initial values for beginning oil availability, decision rules computed in the rational expectations model and the production shock series, we simulate the model to solve for optimal choice of storage levels and export flows in each region and the model yields spot prices and price expectations in each region. We present the simulated storage levels, spot prices, export flows, and inter-temporal price spreads in Figure 9.

From the simulation results, it is apparent that in the first regime, WTI and Brent spot prices are highly correlated, as are inter-temporal price spreads. In the second regime, however, the elevated production in the United States causes U.S. storage to increase and often binds at the maximum storage level. In Europe, the decreased production results in decreased storage levels which often bottom out at zero. As these storage markets bind at the 
Figure 8: Competitive Storage Model - Production Shocks

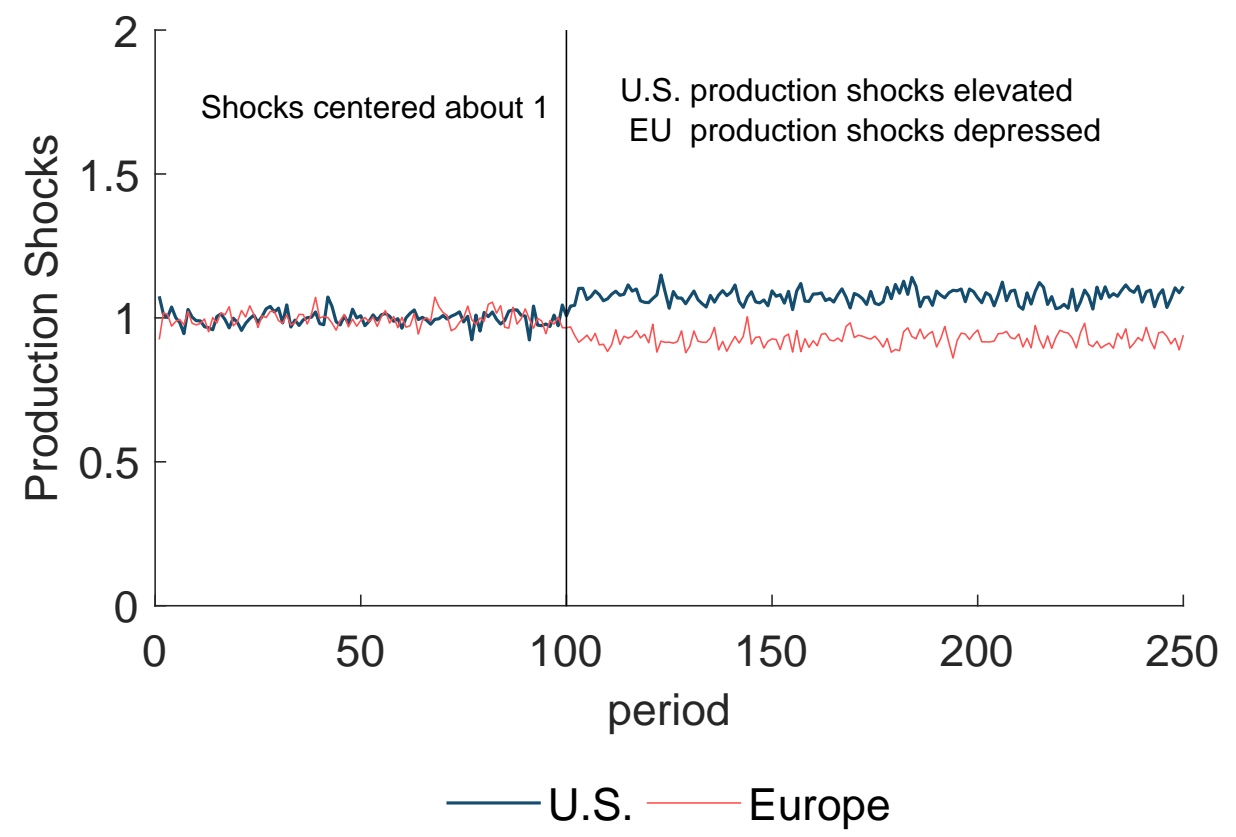

maximum and minimum possible storage levels, the opportunity for inter-temporal arbitrage vanishes. Further, exports from Europe to the United States go to zero in period two as Europe is experiencing a supply disruption and the spatial arbitrage opportunity in this case would be to export oil out of the United States and deliver to Europe. ${ }^{9}$ Due to the crude oil export ban, this was impossible. While U.S. exports of petroleum products (e.g. gasoline, diesel, etc.) are permitted, this mode of spatial arbitrage was insufficient to correct the price disparity, possibly due to the fact that refinery utilization rates at the WTI delivery point were already at 90\% and above in 2011.

In this scenario in which all inter-temporal and spatial methods of arbitrage are

\footnotetext{
${ }^{9}$ Storage and export levels reaching zero is a limitation of the modeling framework. In practice, storage levels do not typically reach zero as there are physical requirements on minimum storage levels for floating roof style storage facilities as well as storage amounts held for operational reasons. In terms of exports, there are several possible reasons why EU producers would continue to ship oil to the U.S. even if the arbitrage conditions suggest they would be doing so at a loss. One possibility is that EU producers might have longterm contracts with U.S. buyers. Nevertheless, the general result of EU storage levels and exports decreasing substantially is consistent with the observed stylized facts.
} 
Figure 9: Simulation Results - Price, Storage, Exports, Spread, \& Production
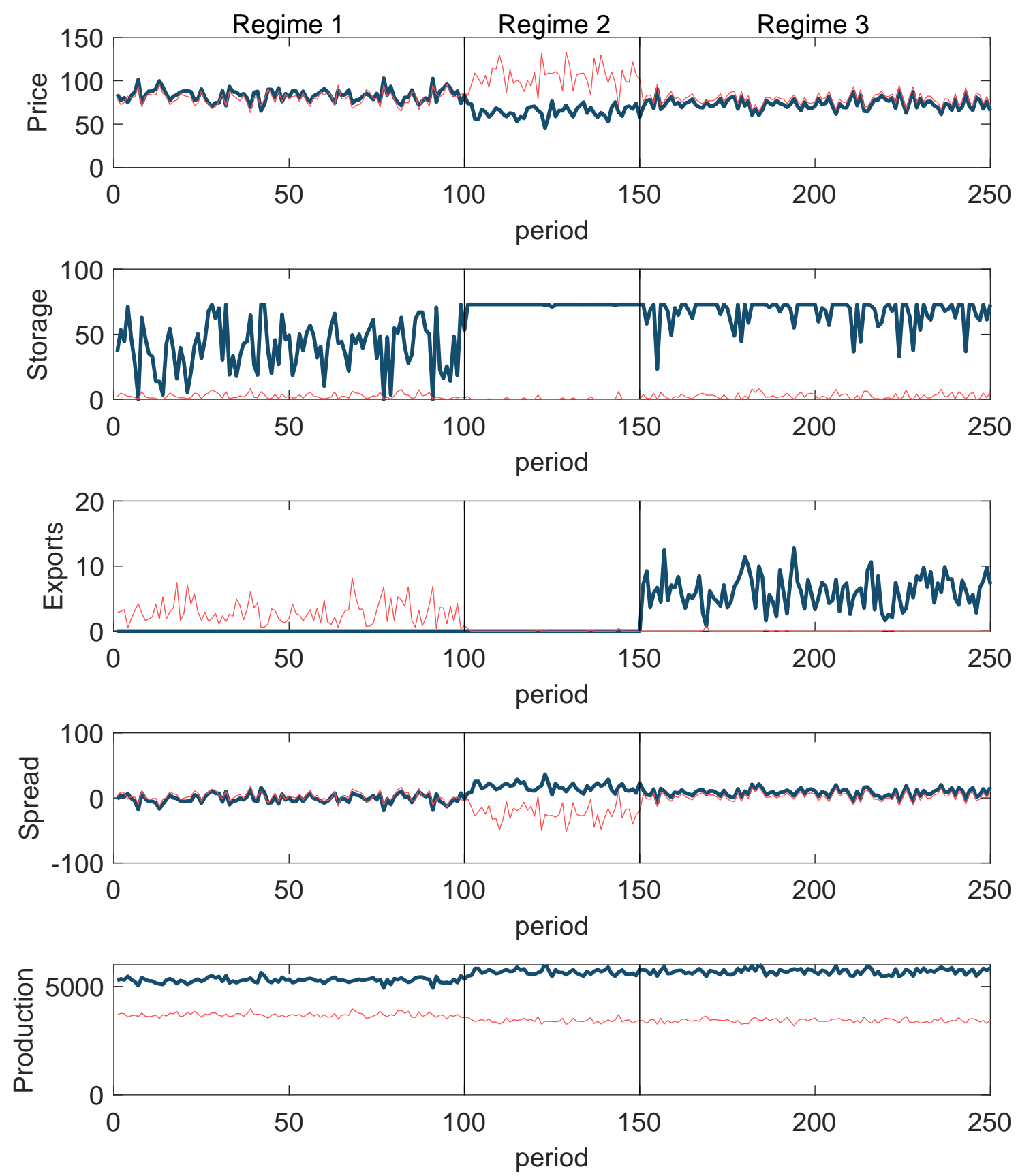

—U.S. - Europe

Note: Regime 1 is the reference case where production is unaltered and the export ban is in place. Regime 2 has U.S. production elevated, EU production depressed, and the export ban in place. Regime 3 has U.S. production elevated, EU production depressed, and no export ban. Price is in USD per barrel, storage is in millions of barrels, exports are in thousands of barrels per day, spread is in USD per barrel, and production is in thousands of barrels per day. 
unavailable, the spot prices of these near identical grades of crude separate. The price in the United States falls, the price in Europe rises and the inter-temporal spreads in these regions take on opposite shapes. The simulation results replicate the situation where the WTI price is lower than Brent, WTI is in contango, Brent is in backwardation, U.S stocks reach the maximum, European stocks are drawn down to the minimum, and trade from Europe to the U.S goes to zero.

In the third regime where U.S. production is elevated, EU production depressed, and no export ban, the U.S. is able to take advantage of the spatial arbitrage opportunity. Following the repeal of the export ban, the simulation indicates oil flowing from the U.S. to the EU, storage levels falling in the U.S., storage levels climbing in the EU, and prices and price spreads converging back together.

\subsection{Robustness Check}

We consider the scenario where instead of a structural change in supply, we implement a structural shift in demand. Our original specification implements the structural change in supply by shifting the means of the multiplicative supply shocks in Equation 10 from $\mu$ to $\mu^{\prime}$. In this specification, we leave the mean of the shock distribution constant at $\mu$ and shift out the EU demand and shift in the U.S. demand, reflecting the change in demand due to the reweighting of commodity indices and the increase in Japanese demand. Simulating the model under this alternate specification yields equivalent results in terms of separation of spot prices, cessation of international trade, hitting storage maximum and minimum levels, and yielding opposite price spreads during the period where the structural change is implemented and the export ban is in place. Additionally, we have run a specification where both supply and demand are shifted simultaneous and find similarly that our results are preserved. 


\section{Conclusion}

The WTI and Brent contracts compete for the role as the world benchmark price of oil. Traders, including hedgers, typically choose one or the other contract. This means there is great interest in the WTI-Brent pricing structure, including the shape of the two futures curves, the absolute price difference between the two benchmarks, and the dynamics of the degree of integration of the markets. These markets are heavily traded (directly and indirectly) by hedgers and financial investors. Prices of jet fuel, heating oil, diesel, and gasoline follow these markets closely. And there are also a large number of derivative financial products such as swaps and options based on either WTI or Brent, or based on the price spread between them.

From early 2011, the price of WTI went to a significant discount to Brent, but U.S. crude could not be exported to the world market to arbitrage away the spread. This break in the pricing relationship arose largely because of expanded U.S. production, reduced production of Brent, and storage capacity factors. For similar reasons, the shape of the two futures curves diverged around the same time. WTI was in contango and Brent displayed backwardation. We develop a simulation model that explains the change in the pricing structure in 2011. The key stylized facts of the WTI and Brent pricing structure are replicated with our model. This means the break in the WTI-Brent futures pricing structure can be explained by standard commodity storage theory.

Since the break in the WTI-Brent relationship, a number of fundamental changes have occurred in the U.S. crude oil infrastructure. In May 2012, a major pipeline connecting the WTI terminal in Cushing, OK to the Gulf Coast reversed it flow direction allowing crude to be sent from the WTI terminal to the coast. In December 2015, U.S. Congress lifted the crude oil export ban. Given that the barriers to spatial arbitrage in the WTI-Brent market have been lifted, the 2011 market segmentation in the crude oil market is unlikely to 
349 reoccur. As a result, the arguments for abandoning WTI as the main crude benchmark have

350 been corrected, and the arguments against using Brent as the main global crude benchmark 351 remain.

\section{Acknowledgments}

$353 \quad$ We appreciate the helpful comments provided by Christopher Thiem at the 2016 354 ECOMFIN conference at Essec Business School. 


\section{References}

Alquist, Ron, and Justin-Damien Guénette. 2014. "A blessing in disguise: The implications of high global oil prices for the North American market." Energy Policy, 64: 49-57.

Blas, Javier, and David Blair. 2011. "European crude stocks hit multiyear low." Financial Times. Available at https://www.ft.com/content/ de085f44-f4a8-11e0-a286-00144feab49a.

BP. 2016. "Sullom Voe Characteristics." Available at http://www. bp. com/en/ global/north-sea-infrastructure/Infrastructure/Terminals/Sullom_Voe/ Characteristics. html.

Brennan, Michael J. 1958. "The supply of storage." The American Economic Review, $50-72$.

Brown, Stephen PA, and Mine K Yücel. 2013. "The shale gas and tight oil boom: Us states' economic gains and vulnerabilities." Council on Foreign Relations. Available at https://www. cfr. org/report/shale-gas-and-tight-oil-boom.

Büyüksahin, Bahattin, Thomas K Lee, James T Moser, and Michel A Robe. 2013. "Physical markets, paper markets and the WTI-Brent spread." The Energy Journal, $34(3): 129$.

Chen, Wei, Zhuo Huang, and Yanping Yi. 2015. "Is there a structural change in the persistence of WT-Brent oil price spreads in the post-2010 period?" Economic Modelling, 50: $64-71$.

Deaton, Angus, and Guy Laroque. 1992. "On the behaviour of commodity prices." The Review of Economic Studies, 59(1): 1-23.

Deaton, Angus, and Guy Laroque. 1996. "Competitive storage and commodity price dynamics." Journal of Political Economy, 896-923. 
Dickey, David A., and Wayne A. Fuller. 1979. "Distribution of the estimators for autoregressive time series with a unit root." Journal of the American statistical association, 74(366a): 427-431.

Elliott, Graham, Thomas J. Rothenberg, and James H. Stock. 1992. "Efficient tests for an autoregressive unit root."

Energy Information Administration. 2015. "Crude oil storage at Cushing, but not storage capacity utilization rate, at record level." Available at https: //www. eia. gov/ todayinenergy/detail. php? $i d=20472$.

Energy Information Administration. 2016a. "International Energy Statistics." Available at https: //www. eia. gov/beta/international/data/browser/.

Energy Information Administration. 2016b. "New England natural gas pipeline capacity increases for the first time since 2010." Available at https://www. eia. gov/ todayinenergy/detail . php? id=29032.

Energy Information Administration. 2016c. "Petroluem and other liquids data." Available at https: //www. eia. gov/petroleum/data. cfm.

Energy Information Administration. 2016d. "Spot Prices." Available at https:// www. eia.gov/dnav/pet/pet_pri_spt_s1_d. htm.

Energy Information Administration. 2016e. "U.S. Crude Oil Imports." Available at $h t t p: / / w w w . e i a \cdot g o v / d n a v / p e t / p e t_{-} m o v e_{-} i m p c u s_{-} a 2_{-} n u s_{-} e p c O_{-} i m O_{-} m b b l_{-}$ m. htm.

Energy Information Administration. 2016f. "U.S. Field Production of Crude Oil Thousand Barrels per Day." Available at https://www. eia.gov/dnav/pet/hist/ LeafHandler. ash $x$ ? $n=$ PETE $s=$ MCRFPUS2E $f=A$. 
Energy Information Administration. 2016g. "Weekly Cushing OK Ending Stocks excluding SPR of Crude Oil." Available at https://www. eia.gov/dnav/pet/hist/ LeafHandler. ash $x ? n=$ PETE $s=W_{-} E P C O_{-} S A X_{-} Y C U O K_{-} M B B L E f=W$.

Engle, Robert F, and Clive WJ Granger. 1987. "Co-integration and error correction: representation, estimation, and testing." Econometrica, 251-276.

Fattouh, Bassam. 2010. "The dynamics of crude oil price differentials." Energy Economics, $32(2): 334-342$.

Gardner, Bruce L. 1979. Optimal stockpiling of grain. Lexington Books.

Gouel, Christophe. 2012. "RECS: Matlab solver for rational expectations models with complementarity equations." Available at https://github.com/christophe-gouel/ recs.

Gregory, Allan W, and Bruce E Hansen. 1996. "Residual-based tests for cointegration in models with regime shifts." Journal of econometrics, 70(1): 99-126.

Gustafson, Robert L. 1958. Carryover levels for grains: a method for determining amounts that are optimal under specified conditions. Technical Bulletin No. 1178, US Department of Agriculture. Available at https: //naldc. nal. usda. gov/download/CAT87201112/ $P D F$.

International Energy Agency. 2012. "Oil Market Report Tables - February." Available at https://www.iea.org/media/omrreports/tables/2012-02-10.pdf.

International Energy Agency. 2016. "Oil Market Report Tables - February." Available at https://www.iea.org/media/omrreports/tables/2016-02-09.pdf.

Kilian, Lutz. 2016. "The impact of the shale oil revolution on US oil and gasoline prices." Review of Environmental Economics and Policy, 10(2): 185-205. 
Makki, Shiva S, Luther G Tweeten, and Mario J Miranda. 1996. "Wheat storage and trade in an efficient global market." American Journal of Agricultural Economics, 78(4): 879-890.

Meyer, Gregory. 2011. "Oil traders unravel Cushing mystery." Financial Times. Available at https: //www. ft. com/ content/ca18995e-f5b1-11e0-be8c-00144feab49a.

Miranda, Mario J, and Joseph W Glauber. 1995. "Solving stochastic models of competitive storage and trade by Chebychev collocation methods." Agricultural and Resource Economics Review, 24(1): 70-77.

Olsen, Knut. 2012. Characterisation and taxation of cross-border pipelines. IBFD.

Scheid, Brian. 2014. "Could a Jones Act waiver move US crude export policy?" SESP Global Platts. Available at http: //blogs.platts. com/2014/10/03/jones-act-waivers/.

The Intercontinental Exchange. 2013. "ICE Brent Crude Oil: Frequently Asked Questions." Available at http://www. theice. com/publicdocs/futures/ICE_Brent_ FAQ. pdf.

Vidal, John. 2011. "Shell's failure to protect Nigeria pipeline 'led to sabotage'." The Guardian. Available at https://www. theguardian. com/environment/2011/aug/ 25/shell-oil-export-nigeria-pipeline-sabotage.

Wilmoth, Adam. 2012. "Cushing, OK stores more than $\$ 4.1$ billion in oil." The Oklahoman. Available at http://newsok. com/article/3660501.

Working, Holbrook. 1949. "The theory of price of storage." The American Economic Review, 1254-1262.

Wright, Brian D, and Jeffrey C Williams. 1982. "The roles of public and private storage in managing oil import disruptions." The Bell Journal of Economics, 341-353. 
${ }_{448}$ Ye, Shiyu, and Berna Karali. 2016. "Estimating relative price impact: The case of Brent 449 and WTI." 